\title{
Abordagens construtivistas no processo ensino-aprendizagem nos Anos Finais do Ensino Fundamental a partir da análise do Projeto Político Pedagógico
}

Constructivist approaches in the teaching-learning process Final Years of Elementary School from

the analysis of the Political Pedagogical Project

Enfoques constructivistas en el proceso de enseñanza-aprendizaje de los Últimos Años de la Educación Básica desde el análisis del Proyecto Político Pedagógico

\author{
Simone de Sousa Moraes \\ ORCID https://orcid.org/0000-0003-1695-9374 \\ EMEF-Professora Selva Campos Monteiro, Brasil \\ smnmoraes@hotmail.com.br \\ Suzana Maria Loures de Oliveira Marcionílio \\ ORCID: https://orcid.org/0000-0001-7177-380X \\ Instituto Federal Goiano, Brasil \\ E-mail: suzana.loures@ifgoiano.edu.br \\ Rosenilde Nogueira Paniago \\ ORCID: https://orcid.org/0000-0003-1178-8166 \\ Instituto Federal Goiano, Brasil \\ E-mail: rosenilde.paniago@ifgoiano.edu.br
}

\begin{abstract}
Resumo
Esta pesquisa teve como objetivo identificar se as ações educativas para o processo ensino-aprendizagem, previstas no Projeto Político Pedagógico (PPP) de uma escola da rede municipal de Rio Verde-GO, são balizadas na abordagem construtivista. O estudo faz parte do Programa de Pós-graduação em Formação de Professores e Práticas Educativas do Instituto Federal Goiano, Campus Rio Verde. Para tanto, foi conduzida pela seguinte questão: Quais as ações educativas para o ensino-aprendizagem esboçadas no PPP são sinalizadoras de uma abordagem construtivista? De abordagem qualitativa, utilizou-se como procedimento metodológico a análise de documento. Os resultados iniciais sinalizam que no PPP há resquícios de uma abordagem construtivista traduzidos pelo incentivo ao trabalho com projetos de ensino e pelo incentivo ao aluno como protagonista na construção de sua aprendizagem. Contudo, no documento, não há clareza sobre quais elementos teóricos e metodológicos do construtivismo são suporte às práticas de ensino dos professores e à proposta pedagógica de modo geral.
\end{abstract}

Palavras-chave: Projeto político pedagógico; Construtivismo; Ensino; Aprendizagem.

\begin{abstract}
This research aimed to identify if the educational actions for the teaching-learning process, provided in the Political Pedagogical Project (PPP) of a municipal school in the city of Rio Verde-Go, are based on the constructivist approach. It is part of the Postgraduate Program in Teacher Training and Educational Practices of the Instituto Federal Goiano, Rio Verde Campus. To do so, it was conducted by the following question: Which educational actions for teaching-learning outlined in the PPP are signs of a constructivist approach? The methodological procedure used was document analysis. The initial results indicate that in the PPP there are traces of a constructivist approach translated by the incentive to work with teaching projects and by the incentive to the student as the protagonist in the construction of his learning. However, in the document, there is no clarity about which theoretical and methodological elements of constructivism support the teaching practices of teachers and the pedagogical proposal in general.
\end{abstract}

Keywords: Political pedagogical project; Constructivism; Teaching; Learning.

\section{Resumen}

Esta investigación tuvo como objetivo identificar si las acciones educativas para el proceso de enseñanza-aprendizaje, impartidas en el Proyecto Político Pedagógico (PPP) de una escuela de la red municipal de Río Verde-GO, están orientadas por el enfoque constructivista. El estudio forma parte del Programa de Postgrado en Formación Docente y Prácticas Educativas del Instituto Federal Goiano, Campus Rio Verde. Para ello, se llevó a cabo mediante la siguiente pregunta: ¿Qué acciones educativas para la enseñanza-aprendizaje planteadas en el PPP son signos de un enfoque constructivista? En un enfoque cualitativo, se utilizó como procedimiento metodológico el análisis de documentos. Los resultados iniciales señalan que en el PPP hay rastros de un enfoque constructivista traducido por el incentivo al 
trabajo con proyectos de enseñanza y por el incentivo al alumno como protagonista en la construcción de su aprendizaje. Sin embargo, en el documento no hay claridad sobre cuáles son los elementos teóricos y metodológicos del constructivismo que apoyan las prácticas de enseñanza de los docentes y la propuesta pedagógica en general.

Palabras clave: Proyecto pedagógico político; Constructivismo; Enseñanza; Aprendizaje.

\section{Introdução}

Esta pesquisa tem como objeto de estudo a abordagem construtivista nas ações educativas de uma escola municipal de ensino fundamental de Rio Verde, Go. Diante as inúmeras e constantes dificuldades enfrentadas pelo professor na sala de aula, em encontrar um método próprio e eficaz para trabalhar com os alunos das primeiras séries do ensino fundamental, o construtivismo se destaca com grande relevância nesta árdua empreitada. Tal fato se justifica, vez que, nesta faixa etária, os educandos se encontram em fase de formação, reconhecimento e desenvolvimento de suas habilidades cognitivas, o que requer uma maior atenção e cuidado por parte do educador.

Notadamente, a essência desta abordagem pedagógica é fazer com que o ensino esteja ao alcance de cada aluno, com aulas interativas e democratizadas, mediadas pelo professor, respeitando suas dificuldades, diferenças individuais e culturais, bem como valorizando seus esforços, independentemente de seus erros ou acertos. Conforme extraímos dos ensinamentos de Niemann e Brandoli (2012), sobre práticas pedagógicas, baseadas nas teorias construtivistas, cada aluno carrega em si uma bagagem de conhecimentos e experiências vivenciadas no seu dia a dia, no âmbito familiar e social, que podem ser utilizadas nas salas de aulas como temas/objetos de estudos, tornando as aulas mais valorizadas e significativas.

Zabala (1998, p.90), por sua vez, nos explica que a concepção construtivista se opõe à tradicional, uma vez que segundo esta concepção "ensinar envolve estabelecer uma série de relações que devem conduzir à elaboração, por parte do aprendiz, de representações pessoais sobre o conteúdo objeto de aprendizagem”.

Logo, a teoria construtivista se opõe às práticas pedagógicas tradicionais, valorizando as experiências e conhecimentos prévios trazidos pelos alunos, procurando reconhecê-los como agentes ativos no processo de ensinoaprendizagem, e não como meros ouvintes, ao passo que os estimulam a pensar de forma crítica e os encorajam a encontrar respostas para os problemas propostos dentro e fora da sala de aula. (Gregório; Pereira, 2012).

No processo ensino-aprendizagem de abordagem construtivista, a relação entre alunos e professores se dá de forma harmoniosa e de respeito mútuo, sem a tradicional postura autoritária do professor. $\mathrm{O}$ educador se coloca na condição de mediador do conhecimento e não como dono deste. Uma interação constituída conforme defendia Freire (1996) em que a relação acontece de forma horizontal dialógica, e não vertical como no ensino tradicional. A sala de aula, que antes era tão silenciosa, se torna um lugar de experimentação, de espontaneidade, e de inquietação do aluno. (Marinho, 2016)

As atividades desta teoria de ensino são voltadas para debates e exposições orais ou escritas, valorizando a opinião de cada indivíduo, dispensando as tradicionais e exaustivas práticas avaliativas, através de testes e provas escritas, sendo estas substituídas pela observação direta do desempenho de cada aluno. Os erros são vistos como estágios do processo de aprendizagem, tendo o condão de balizar as atividades avaliativas, não sendo considerados como déficit de conhecimento ou falta de atenção.

Na abordagem construtivista, os alunos são estimulados e encorajados a expressar suas próprias ideias e experiências, previamente adquiridas, as quais serão compiladas e, em seguida, inseridas como parte dos conteúdos ministrados na aula. Essa prática de ensino faz com que os alunos desenvolvam suas capacidades intelectuais, por meio da participação direta nas aulas, deixando a condição de meros telespectadores e se tornando agentes protagonistas de sua própria aprendizagem.

Em face das contribuições acerca da abordagem construtivista no processo ensino-aprendizagem da educação básica, os elementos motivadores para a realização desta pesquisa são advindos de nossas experiências como professoras e pesquisadoras em que nos inquietamos em buscar a melhor forma de trabalharmos os conteúdos para que verdadeiramente haja 
aprendizado por parte dos alunos. Isto se deu após a constatação de que o ensino tradicional já não atende à expectativa das crianças e adolescentes que, para aprender, estão ficando cada vez mais exigentes quanto a compreensão de cada informação apresentada no que se refere a utilização deste para o seu dia a dia.

Por fim, por acreditarmos na abordagem construtivista como uma tendência teórica que procura atender e suprir as necessidades e anseios dos alunos, tornando as aulas mais divertidas e significativas para eles, procuramos desenvolver esta pesquisa, com a hipótese de que práticas de abordagens construtivistas se materializam no cotidiano escolar, caso elas estejam previstas em ações vinculadas no Projeto Político Pedagógico (PPP) da escola.

Destacamos a compreensão de que o PPP não é algo que tenha como finalidade apenas o cumprimento de tabelas burocráticas. E, se bem formatado, contribui para transformar a realidade escolar em uma realidade muito melhor. (Gurgel 2009). Em concordância com Gurgel (2009), Veiga (2013, p.13) afirma que o PPP, por ser um documento vivo, "é construído e vivenciado, em todos os momentos, por todos os envolvidos com o processo educativo da escola" (Veiga, 2013, p.13). É, pois, um documento que exprime uma gestão democrática em que todos os integrantes da comunidade educativa participam de sua elaboração em um processo constante de mudanças e (re) formulação.

Em face do exposto, a pesquisa teve como objetivo identificar se as ações educativas para o processo ensinoaprendizagem, previstas no PPP, são balizadas na abordagem construtivista. Para tanto, foi conduzida pela seguinte questão: Quais as ações educativas para o ensino-aprendizagem, esboçadas no PPP, são sinalizadoras de uma abordagem construtivista?

Para efeitos de organização do texto, optamos por inicialmente apresentar a trajetória metodológica da pesquisa, seguida de um breve enquadramento teórico e dos resultados da pesquisa.

\section{Metodologia}

O presente estudo trata-se de uma pesquisa qualitativa. No contexto da pesquisa científica, segundo Oliveira (2008), há duas vertentes diferentes, sendo uma a pesquisa quantitativa e a outra a pesquisa qualitativa. Com uma visão totalmente positivista, a pesquisa quantitativa, para a comprovação dos objetivos gerais da pesquisa, apresenta seus dados baseando-se em números e cálculos matemáticos. Já a pesquisa qualitativa, com uma visão interpretacionista, embasa-se na peculiaridade subjetiva, valorizando o uso de narrativas escritas ou faladas, apresentando, também, como objetivo a descoberta de pontos de vista, opiniões e impressões.

Em concordância com Oliveira (2008), as autoras, Lüdke e André (2013) afirmam que a pesquisa qualitativa em educação apresenta como características básicas: o ambiente natural como sua fonte e o pesquisador como a principal ferramenta; os dados coletados são descritivos; valorização do procedimento da execução da pesquisa maior que o resultado, tendo como foco uma atenção especial, pelo pesquisador; a importância que as pessoas dão às coisas e às suas vidas e a predisposição do emprego do processo indutivo na análise dos dados.

No caso da presente pesquisa utilizamos como procedimento a análise de documento, nomeadamente o Projeto Político Pedagógico (PPP) do ano de 2019 de uma escola da rede municipal de Rio Verde/GO. Para tanto, baseamo-nos em referenciais teóricos obtidos a partir de indexados em livros e periódicos que abordam a temática em questão, ou seja, as práticas pedagógicas construtivistas.

Para Lüdke e André (2013), a análise documental é ferramenta de grande importância para a pesquisa qualitativa, sendo considerada como uma técnica decisiva para pesquisas feitas nas áreas de ciências sociais e humanas. Essas pesquisas são realizadas através de análise preciso de documentos diversos que são considerados cientificamente fidedignos e que, como vantagem com relação às demais ferramentas, esses documentos, por serem inalteráveis, podem ser consultados várias vezes e não apresentam custo algum. 
Para Calado e Ferreira (2004/2005), a análise de documentos pode ser usada para servir de dados complementares ou ser o método principal utilizado na pesquisa. No caso específico desta pesquisa, o documento foi a fonte principal dos dados recolhidos. Assim, no processo de pesquisa, procuramos desenvolver a recolha dos dados e análise conforme orienta Calado e Ferreira (2004/2005), ao elucidar que a análise é composta por dois momentos: a recolha e a análise de documentos. Para além, com base nos autores, no processo, procuramos não apenas recolher o documento para obter as informações necessárias. Ao contrário, o PPP foi estruturado e manuseado para a identificação das principais categorias, tendo como base as questões e objetivos da pesquisa.

No que tange à análise de conteúdo, Calado e Ferreira (2004/2005) a conceitua como um grupo de ferramentas determinadas a criação de um texto analítico referente ao material coletado, podendo essa análise de conteúdos ser dividida em três tópicos: redução de dados, apresentação de dados e conclusões. Na redução de dados, acontece a separação das unidades permitindo ao pesquisador fazer a classificação de acordo com o tema em análise, passando pelos processos de separação em unidades, categorização/codificação e agrupamento.

Segundo Lüdke e André (2013), para fazer a análise de conteúdo, é necessário a manipulação de todo material adquirido durante a pesquisa. Essa tarefa de análise requer:

[...] num primeiro momento, a organização de todo o material, dividindo-o em partes, relacionando essas partes e procurando identificar nele tendências e padrões relevantes. Num segundo momento essas tendências e padrões são reavaliados, buscando-se as relações e inferências num nível de abstração mais elevados. (Lüdke \& André, p.53, 2013).

Considerando as ponderações indicadas por Calado e Ferreira (2004/2005) acerca da análise de documentos e de conteúdo, bem como Lüdke e André (2013) ao afirmarem que a categorização é um procedimento de organização de dados que os agrupa considerando alguma parte em comum entre eles, elaboramos um roteiro para a análise do PPP e categorização dos dados com questões estruturadas a partir da questão e objetivos da pesquisa.

Quadro 1 - Roteiro da análise do PPP:

\begin{tabular}{|c|c|c|c|}
\hline Objetivos & Pergunta principal & Perguntas complementares & Categorias/subcategorias \\
\hline $\begin{array}{l}\text { Analisar as ações de } \\
\text { ensino-aprendizagem } \\
\text { esboçadas no Projeto } \\
\text { Político Pedagógico } \\
\text { (PPP) que são de } \\
\text { abordagens } \\
\text { construtivistas }\end{array}$ & $\begin{array}{l}\text { Quais as ações de ensino- } \\
\text { aprendizagem esboçadas no } \\
\text { PPP são sinalizadoras de } \\
\text { uma abordagem } \\
\text { construtivista? }\end{array}$ & $\begin{array}{l}\text { Quais os pontos relevantes do PPP } \\
\text { que contribuem para a mudança da } \\
\text { postura didática do professor em } \\
\text { sala de aula? } \\
\text { Quais são objetivos para o ensino } \\
\text { são previstos no PPP? Em que } \\
\text { medida eles se amparam na } \\
\text { abordagem construtivista? } \\
\text { Quais as propostas metodológicas } \\
\text { sinalizadas no PPP podem se } \\
\text { configurar em uma abordagem } \\
\text { construtivista? } \\
\text { Como são propostas as } \\
\text { abordagens para os conteúdos de } \\
\text { ensino? }\end{array}$ & $\begin{array}{l}\text { 1. Ações de ensino-aprendizagem } \\
\text { propostas no PPP são sinalizadoras de } \\
\text { uma abordagem construtivista } \\
\text { 1.1Objetivos de ensino propostos no } \\
\text { PPP que configuram uma abordagem } \\
\text { de ensino construtivista } \\
\text { 1.2 Propostas metodológicas } \\
\text { sinalizadas no PPP que configuram } \\
\text { uma abordagem de ensino } \\
\text { construtivista }\end{array}$ \\
\hline
\end{tabular}

Fonte: Autores.

\section{Práticas Educativas de Abordagens Construtivistas: Alguns Elementos Teóricos}

$\mathrm{Na}$ busca de elementos teóricos que tratam da tendência construtivista, procuramos nos amparar em alguns teóricos, tais como Zabala (1998), Bessa (2008), Mastella et al., (2014), Paniago (2017), Freire (1996), Vygotsky (1991) e Gregório e 
Pereira (2012). Além dos teóricos supracitados, fizemos a pesquisa teórica com busca em bancos de dados, como a Biblioteca Digital Brasileira de Teses e Dissertações (BDTD) do Instituto Brasileiro de Informação em Ciência e Tecnologia (IBCIT), Banco de Teses da Coordenação de Aperfeiçoamento de Pessoal de Nível Superior (CAPES), Scientific Electronic Library Online (SCIELO), Google Acadêmico e Associação Nacional de Pós-graduação e Pesquisa em Educação (Anped), dentre outros em que destacamos Santos (2007) e Chakur (2004), Niemann e Brandoli (2012).

A começar, elucidamos que o construtivismo é definido como uma teoria da aprendizagem desenvolvida na Rússia, em meados dos anos 60 (século XX), pelo suíço biólogo e filósofo Jean Piaget, com o propósito de explicar o desenvolvimento da inteligência humana.

Segundo esta teoria, conforme estudos realizados, com crianças de até 12 anos de idade, por Jean Piaget, o conhecimento não é nato, mas sim algo advindo da interação do sujeito com o meio em que ele vive (Niemann; Brandoli, 2012). De acordo com as autoras, Piaget afirma que a criança deve participar ativamente na construção de seu próprio conhecimento para que esta se torne em indivíduo autônomo e solidário para com a formação de uma sociedade mais justa.

Niemann e Brandoli (2012) relatam que diante de tal afirmação, feita por Piaget, se faz necessário o rompimento com alguns paradigmas da educação, dentre eles a mudança da tradicional prática escolar, de que o professor é considerado o centro das atenções, oportunizando ao aluno uma participação mais ativa das aulas por meio de leituras de textos, trabalhos em grupos e outras atividades que o permitam expor suas ideias, individualmente ou em grupos, de forma democrática e interativa. Os autores Souza e Silva (2021), somando aos ensinamentos de Niemann e Brandoli (2012), destacam que os alunos além de serem diferentes uns dos outros quanto a capacidade de adquirir conhecimentos, podem apresentar também dificuldades em sua carreira escolar devido a questões emocionais, psicomotoras e familiares.

As autoras Chakur, Silva e Massabni (2004), em seus relatos, discorrem que a Lei de Diretrizes e Bases da Educação Nacional teve seu início em 1971 (LDB 5692/71) dando grande importância à teoria piagetiana e seus estágios de desenvolvimento cognitivo como propostas curriculares de ensino. No entanto, segundo Chakur, Silva e Massabni (2004), os conceitos e considerações piagetianos foram apropriadas de uma forma descontextualizada e com significados diferentes dos originais, possibilitando a criação de jargões, tais como alguns citado a seguir:

[...] no Construtivismo o professor tem papel de animador (motivar o aluno), que qualquer assunto trazido pelo aluno deve ser objeto de ensino-aprendizagem e que o conteúdo não deve ser imposto ao aluno. Essas últimas ideias, entre outras, parecem advir de certos slogans bastante difundidos nas escolas: deve-se partir do interesse, partir da realidade do aluno, de sua bagagem, daquilo que ele traz de casa. (Chakur; Silva \& Massabni, 2004, p.15).

Vale ressaltar que a teoria de Piaget não é voltada para a ação pedagógica, e sim para a construção do sujeito epistêmico. Porém, após a constituição da Psicologia como uma disciplina científica, foi criada a expectativa de que a psicologia seria o suposto científico necessário para abordar questões referentes à Educação dando origem a várias correntes teóricas, com certa hegemonia, em países e épocas diferentes (Chakur; Silva \& Massabni, 2004).

As autoras prosseguem com suas contribuições afirmando que Piaget define a inteligência como o resultado de um esquema de assimilação de estrutura que dá ao sujeito permissão para melhor compreensão e organização do mundo por meio dos mecanismos de assimilação e acomodação. Este esquema acontece "mediante os processos de assimilação (incorporação aos esquemas/ estruturas presentes no ambiente) e a acomodação (modificação de esquemas/estruturas) para ajustá-los às exigências ambientais" (Chakur; Silva \& Massabni, 2004, p.4).

Para Mastella et al. (2014), é indiscutível a contribuição de Piaget, com suas pesquisas sobre desenvolvimento humano, para as práticas pedagógicas por meio dos estágios da aprendizagem e a construção da moralidade, esclarecendo que o principal objetivo da educação, de acordo com esta teoria, é criar cidadãos com a competência para além de memorizar, que 
tenham autonomia para a criação, invenção e produção de novos conhecimentos. E quanto a nós professores, é de extrema importância reconhecermos que o nosso público é composto de indivíduos diferentes e com tempos diferentes, para tanto é preciso "[...] respeitar o desenvolvimento do aluno e a forma como este aprende. É importante também conhecer como o sujeito organiza em sua estrutura cognitiva as informações recebidas do meio" (Mastella; et al., 2014, p.11). E em razão disso, precisamos oferecer diferentes formas de trabalhar os conteúdos para que o aluno tenha condições de construir seu conhecimento segundo suas habilidades, levando em consideração a base que cada um tem acerca do que está sendo ensinado (Guimarães \& Maciel, 2021).

Santos (2007), por sua vez, destaca que o construtivismo colabora com a solução de alguns problemas pedagógicos por ter como objetivo estimular o aluno a reconstruir o conhecimento previamente existente para que, a partir daí, adquira um novo conhecimento, levando em consideração o fato de que, segundo a este entendimento, a aprendizagem se dá por meio da formação de imagens mentais, produzidas pela interação do mundo psicológico do indivíduo com o meio externo em que ele vive.

Assim, Santos (2007) preceitua que a corrente pedagógica conhecida como construtivista propôs novas formas de organizar a escola a partir dos conhecimentos desenvolvidos por Piaget e Vygotsky sobre a criança. E o autor prossegue elucidando que, de acordo com a teoria construtivista, o erro é visto como um recomeço, porém a rigidez nos procedimentos de ensino e as avaliações padronizadas são fortemente condenadas, pois, nessa teoria, as disciplinas são voltadas para a reflexão e auto avaliação. Este entendimento levantou um questionamento sobre a escola tradicional, despertando a necessidade de deixar a crença de que o professor é o principal agente transmissor de conhecimento e o aluno, um mero receptor passivo e vazio (Santos, 2007).

E por fim, segundo Santos (2007), o construtivismo, para alguns autores, é visto em dois ângulos de interação recíproca: o sujeito histórico e o objeto cultural, sendo realçado também por considerar que o processo de aprendizagem deve ocorrer de forma significativa. Assim, para que a aprendizagem verdadeiramente aconteça, é necessário que o professor faça um diagnóstico referente ao conhecimento prévio do aluno, através da coleta de informações.

Nesta seara de discussão teórica, reportamos também a Bessa (2008, p. 94), ao destacar que "O aprendizado da criança começa muito antes dela frequentar a escola. Qualquer situação de aprendizado com a qual a criança se defronta na escola tem sempre uma história prévia", não bastando apenas inseri-la em um ambiente estimulador e de forma isolada. Para que efetivamente ocorra a aprendizagem, se faz necessário a interação com outros indivíduos, a fim de que possa internalizar o processo social e cultural, dando início ao processo de conhecimento, que não ocorre de forma espontânea, e sim por intermédio das trocas de experiências entre os alunos (Bessa, 2008).

Com a contribuição de Bessa (2008), em conformidade com Souza e Rosso (2011), apresentaremos outro grande percursor do Construtivismo que foi Lev Semionovitch Vygotsky que, ao contrário de Piaget, defende que o conhecimento se dá, não apenas por meio da interação do indivíduo com o objeto, mas, sim, através deste com o meio social e cultural em que vive; definindo a aquisição da aprendizagem como o resultado do processo interpessoal e não interno do indivíduo. Dessa forma, os estudos de Vygotsky são decorridos da compreensão da formação do homem em contato com a sociedade, por intermédio de experiências pessoalmente significativas, e não de forma isolada (Bessa, 2008).

Ainda a respeito de Vygotsky, buscamos Santos (2007) que enfatiza que para Vygotsky o papel do professor é ensinar ao aluno aquilo que este não consegue aprender sozinho, é decodificar a linguagem científica, tornando-a de acessível compreensão. Tal processo é explicado através da Zona de Desenvolvimento Proximal (ZPD) que, sendo um conceito elaborado por Vygotsky, tem como função definir aquelas funções que ainda não amadureceram, mas que estão em processo de maturação (Santos, 2007). 
Então, é o próprio Vygotsky (1991, p. 56) que vem contribuir com esta discussão ao esclarecer que "o aprendizado da criança começa muito antes dela frequentar a escola. Qualquer situação de aprendizado com a qual a criança se defronta na escola tem sempre uma história prévia". Assim como Piaget, Vygotsky também defende que a criança é um ser ativo no processo de ensino aprendizagem. Contudo, não basta apenas inseri-la em um ambiente estimulador e de forma isolada

Vygotsky (1991) cria conceito da zona proximal de desenvolvimento com o propósito de elaborar as dimensões do aprendizado escolar. Ele definiu a zona proximal do desenvolvimento de hoje como o nível de desenvolvimento real no futuro e para realização desse estudo ele usa como técnica a introdução de obstáculos ou complexidades nas atividades propostas que faz com que a criança tenha que criar outras formas para resolvê-las. Ele utiliza também a técnica de apresentar e dar à criança alternativas para a resolução da situação problema com o auxílio de diferentes tipos de objetos para serem usados durante o teste. Outra técnica também utilizada por Vygotsky foi a de colocar a criança para realizar uma tarefa que fosse muito além de suas habilidades e capacidades cognitivas, buscando dessa maneira proporcionar o início de novas habilidades.

Assim, com a elaboração da teoria de Vygotsky, fica sinalizado ser fator determinante no processo de aprendizagem a integração de crianças em diferentes níveis de desenvolvimento, despertando no aluno que tem menos compreensão do assunto em discussão a impressão de estar sendo desafiado pelo colega que sabe mais, e, com a ajuda do colega, ele realiza atividades que não conseguiria sem ajuda alguma. Isso, no entanto, não dispensa o professor de seu papel, pois lhe é cabido a função de mediador da turma (Vyghotsky, 1991).

Bessa (2008), sob a perspectiva de Vygotsky (1991), afirma que para que efetivamente ocorra a aprendizagem se faz necessário a interação com outros indivíduos, a fim de que possa internalizar o processo social e cultural, dando início ao processo de conhecimento, que não ocorre de forma espontânea, e sim, pelas trocas de experiências entre os alunos (Bessa, 2008).

E nessa discussão ainda consideramos importante recorrer a Zabala (1998) ao afirmar que na abordagem construtivista o principal protagonista é o aluno, que se contrapõe a necessidade de uma atuação igualmente ativa por parte do educador. Nesta concepção de ensino, o educador tem o papel de propiciar condições para que o aluno construa a sua aprendizagem. Para tanto, cita a importância de os professores motivarem os alunos a observarem, problematizarem o seu contexto e a oportunizarem a eles experiências contextualizadas para que o conhecimento possa ser explorado ou analisado de modo a avaliar a situação em toda sua amplitude e reconduzi-la caso seja necessário.

De acordo com Zabala (1998), a prática pedagógica é concebida como uma ajuda ao processo de construção de aprendizagem do aluno, a partir dessa intervenção surgem as zonas de desenvolvimento proximal que orientam os alunos neste percurso. A situação do ensino e aprendizagem auxilia na superação de desafios para além do que se possa perceber.

Para finalizar, destacamos como percursor do ensino construtivista no Brasil, o filósofo e professor Paulo Freire (1996), que, em seus ensinamentos, contempla a teoria piagetiana ao admitir que o indivíduo é sujeito produtor de cultura e conhecimento e, por outro lado, se alinha aos ensinamentos de Vygotsky ao afirmar que a aprendizagem e o saber resultam da relação coletiva e dialética entre indivíduos (Freire, 1997).

Segundo Souza (2015) Paulo Freire acredita no poder de transformação da educação em um mundo de forma política crítica, e, para tanto, defende uma escola democrática possibilitando ao educador e ao educando condições de “[...] dialogar, discutir, questionar e compartilhar o conhecimento, num espaço de transformações, interações, respeitando as diferenças culturais e sociais" (Souza, 2015 p.23).

Na sequência, apresentaremos os resultados da pesquisa. 


\section{Ações de Ensino-Aprendizagem Propostas no PPP e a Sinalização de uma Abordagem Construtivista}

De modo geral, nos dados analisados no PPP, constatamos que não havia evidências teóricas sobre o construtivismo. Contudo, é sinalizado suporte de modo especial nas tendências pedagógicas da linha progressista, pelo que achamos relevante destacar inicialmente. No documento é apresentado que "o grupo de professores não optaram por apenas uma tendência educacional e sim por uma postura eclética baseada nas tendências libertadoras da educação de linha progressista e sóciohistórica" (PPP, 2019, p.6).

Conforme depreendemos, os princípios formativos do documento se baseiam na linha progressista em que concentram tendências pedagógica como a Libertadora de Paulo Freire e sócio-histórica de Dermeval Saviani, pois, segundo o esclarecimento de Paniago (2017), a pedagogia libertadora de Freire prioriza a liberdade do oprimido, defendendo a escola quanto ao seu real papel que é de contribuir para a formação da consciência política do aluno intervindo e transformando a realidade deste.

Quanto a pedagogia sócio-histórica de Dermeval Saviani, segundo Paniago (2017), a escola tem como função a formação de sujeitos capazes de viver em sociedade, independente das várias e diversas contradições existentes, de forma que “[...] os sujeitos sejam preparados para a emancipação por meio dos saberes elaborados historicamente, com vistas a uma participação social ativa" (Paniago, 2017, p.50).

Posto esta reflexão sobre as principais tendências pedagógicas que são evidenciadas no documento, partimos para a apresentação dos dados. Para efeitos de análise e definição das categorias, consideramos as orientações de Paniago (2017) sobre os principais componentes didáticos que envolve o processo ensino-aprendizagem. Para a autora, o processo didático em sala de aula assenta-se na relação ensino-aprendizagem e constituem-se principalmente nos seguintes componentes didáticos: conteúdo da matéria, ação de ensinar e ação de aprender, enfim, as relações entre professor e aluno.

Assim, ao analisar as ações de ensino-aprendizagem, propostas no PPP, sinalizadoras de uma abordagem construtivista e considerando a extensão deste texto, focalizamos a nossa análise em duas subcategorias: 1) Objetivos do ensino propostos no PPP que configuram uma abordagem construtivista; 2) Abordagens metodológicas na perspectiva do construtivismo.

\subsection{Objetivos de Ensino Propostos No PPP que Configuram uma Abordagem de Ensino Construtivista}

Apesar de no documento não aparecer de forma explícita a perspectiva teórica do construtivismo, constatamos evidências, aspectos que sinalizam abordagens construtivistas apresentados nos objetivos.

\footnotetext{
- Despertar no aluno interesse para problemas imediatos do cotidiano, pela observação e apresentar possíveis solúveis, através de situações vivenciadas.

- Provocar a curiosidade do aluno para que ele confronte situações problema numa dimensão espaço/tempo em que se realiza a educação da criança e do jovem, conscientizando-os da importância em respeitar as etapas do desenvolvimento humano.

- Possibilitar a busca de conceitos por meio dos fundamentos da ciência e da tecnologia ao ressaltar os valores universais de convivência e de desenvolvimento pessoal, através do uso de equipamentos tecnológicos (celular, computador e data show) (PPP, 2019, p.7).
}

Fica evidente, portanto, que há uma preocupação por parte da comunidade educativa (gestão, professores e representantes dos segmentos pais e alunos) em oportunizar a formação vinculada com a vida dos alunos de modo a despertar a sua curiosidade e para a resolução de problemas. Tal perspectiva vai ao encontro do que propõe o construtivismo, pois conforme pontua Mastela et al., (2014): 
Nessa perspectiva, é fundamental criar desafios para as crianças, propor situações de aprendizagens que geram uma desacomodação das experiências já assimiladas, implica o envolvimento dos educadores, em estarem atentos ao desenvolvimento de seus educandos independente da área que atuem, e que esses ofereçam e busquem alternativas para que a criança amplie seu horizonte de desenvolvimento, formando sujeitos capazes, autônomos, participativos e atuantes na sociedade em que vivemos, sem discriminação, nem preconceito, valorizando as pessoas pelo que elas são e não pelo que elas têm (Mastela et al., 2014, p.12).

Para além disto, fica evidente no PPP uma preocupação com a formação para além dos aspectos meramente científicos e conceituais, pois, fica sinalizado nos objetivos a relação dos conhecimentos conceituais com os procedimentais, ou seja, com as questões do contexto dos alunos, de modo com que utilizem os conhecimentos estudados para resolver os problemas enfrentados na sua realidade. Zabala (1998) nos ajuda nesta reflexão ao esclarecer que os objetivos do ensino devem contemplar os aspectos conceituais, procedimentais e atitudinais. O aspecto conceitual se refere aos elementos acerca dos conhecimentos científicos trabalhados nos livros didáticos, o aspecto procedimental significa a forma prática, operacional de se materializar os conhecimentos e a questão atitudinal se refere a mudança de atitude, valores a suscitar nos alunos. Também nos ancoramos em Mastella et al., (2014, p. 10) ao elucidar a importância de incitar os alunos a resolver problemas "a todo o momento o sujeito é levado a resolver problemas, dos mais simples aos mais complexos, e isso implica a construção de conhecimentos que permitem resolver tais situações e resolver com sucesso."

No PPP fica sinalizado, ainda, a preocupação da comunidade educativa com aspectos em termos cognitivos, afetivos e socioculturais, explicita no excerto: "competências cognitivas, afetivas, culturais sociais estão presentes na implementação desta proposta de forma que promovam o desenvolvimento da pessoa e qualifiquem o jovem pra vida da sociedade" (PPP, 2019, p.7). Conforme depreende-se, a escola não vai atém apenas a formação puramente conceitual, mas avança para outros aspectos que incluem os valores afetivos e socioculturais. Zabala (1998) contribui com esta análise ao criticar o papel do ensino restrito aos conteúdos científicos, às disciplinas de áreas específicas. Para o autor “Até hoje, o papel atribuído ao ensino tem priorizado as capacidades cognitivas” (Ibid., 1998, p.43). Ao contrário, conforme já pontuamos, o autor defende uma formação ampla que contemple as perspectivas conceituais, atitudinais e procedimentais e a articulação de uma prática reflexiva e coerente, assim como o oferecimento de elementos que possibilitem análise e modificações dessas condições apresentadas.

No documento é explicitado que a proposta se fundamenta em objetivos que focalizam as práticas de ensino em sala de aula, de forma a "identificar valores, distinguir alternativas dadas de comportamento, imaginar outras possíveis, elucidar dilemas, argumentar para defender uma ou outra decisão possível e avaliar causas e consequências das ações” (PPP, 2019, p. 7). Assim, fica evidente a preocupação com o aluno, como o centro do processo ensino-aprendizagem, de forma a torná-lo autônomo no processo de construção de sua aprendizagem, “[...] agente na criação e integrante com o meio ambiente. Constrói a sua autonomia, autodeterminação, responsabilidade, cooperação e solidariedade, aprende a trabalhar em parceria com o grupo, a partilhar ideias, pensamentos e assimila códigos de conduta padronizados de comportamento coletivo" (PPP, 2019, p. 7).

Conforme depreendemos, o excerto acima retirado do PPP traduz uma perspectiva formativa que contempla a abordagem construtivista, na medida em que os alunos são motivados a construir a sua autonomia, a encontrar respostas, a aprender a trabalhar em grupo. Santos (2007) nos ajuda com esta análise ao pontuar que no construtivismo a criança é levada a encontrar respostas de seus questionamentos através da sua interação com a realidade e com os seus colegas, sendo capaz de apresentar noções correspondentes ao que está sendo proposto.

Também Zabala (1998, p.92) contribui com esta reflexão ao elucidar que uma das manifestações da concepção construtivista é "Potencializar progressivamente autonomia dos alunos na definição de objetivos, no planejamento das ações que os conduzirão a eles e em sua realização e controle, possibilitando que aprendam a aprender." 
As intencionalidades vinculadas a autonomia ficam visíveis no documento quando nele é encontrado além de certa preocupação com os aspectos cognitivos, afetivos, socioculturais, é sinalizado também outros aspectos que traduzem a preocupação da comunidade educativa com a formação de cidadãos autônomos

Prosseguindo, encontramos outras evidências de uma formação que contempla uma abordagem construtivista.

A Instituição escolar adequa a sua prática educativa às necessidades sociais, políticas, econômicas e culturais da realidade da comunidade, considerando os interesses e motivações dos alunos. Dessa forma, garante as aprendizagens essenciais para a formação de cidadãos autônomos, críticos e participativos, capazes de atuar com competência, dignidade e responsabilidade no meio em que vivem (PPP, 2019, p. 6).

Assim, fica visível a preocupação com outros valores para além dos conteúdos conceituais, na medida em que são sinalizadas questões acerca da formação de pessoas críticas e participativas. O que vai ao encontro do que propõe Zabala (1998, p.28) ao esclarecer que "Educar quer dizer formar cidadãos e cidadãs, que não estão parceladas em compartimentos estanques, em capacidades isoladas."

Ainda, para além de uma abordagem construtivista, encontramos elementos que sinalizam a visão freiriana de educação (Freire, 1996), porquanto, a visão de formação proposta no documento de um “[...] homem consciente de si, do outro, do mundo, pessoa que tenha condições de posicionar-se criticamente ante a realidade, assumi-la e transformá-la na perspectiva democrática, participativa, reflexiva, ética e humana." (PPP, 2019, p. 9), vai incidir diretamente no processo ensinoaprendizagem dos professores em sala de aula.

Assim, isto retrata a óptica de Freire (1996) que uma das principais tarefas do professor é a não omissão, em sua prática docente, da função de tornar cada vez mais desenvolvida a capacidade crítica do seu alunado tendo como prioridade “[...] trabalhar com os educandos a rigorosidade metódica com que devem se 'aproximar' dos objetos cognoscíveis." (Freire, 1996, p.14) lembrando que "[...] esta rigorosidade metódica não tem nada que ver com o discurso "bancário" meramente transferidor do perfil do objeto ou do conteúdo" (Freire, 1996, p.14).

Na continuidade de análise, verificamos no PPP (2019, p. 17) que "a função da escola é a de proporcionar ao aluno, de maneira intencional, planejada, organizada, sistemática, situações facilitadoras de aprendizagem" Esse excerto mostra que o posicionamento da escola vai ao encontro dos ensinamentos de Vygotsky (1991, p. 62) que afirma que "[...] o aprendizado adequadamente organizado resulta em desenvolvimento mental e põe em movimento vários processos de desenvolvimento que, de outra forma, seriam impossíveis de acontecer."

Conforme relatado no próprio PPP da escola, "[...] o conhecimento não está pronto e acabado e sim em constante processo de construção" (PPP, 2019, p. 17). É da competência escolar o desenvolvimento da habilidade de aprender e a continuidade da ação referida, pois, conforme Vygotsky (1991, p.62) define, "o aprendizado é um aspecto necessário e universal do processo de desenvolvimento das funções psicológicas culturalmente organizadas e especificamente humanas.”

\subsection{Propostas Metodológicas Sinalizadas no PPP que Configuram uma Abordagem de Ensino Construtivista}

No que tange às ações do ensino-aprendizagem, além de fazermos a constatação de que "a escola propõe um trabalho participativo que visa a realização das pessoas envolvidas no ensino - aprendizagem" (PPP, 2019, p. 10) e "uma avaliação qualitativa que presume a participação e envolvimento das pessoas com o seu pensar e agir” (PPP, 2019, p. 11), destacamos os aspectos vinculados a questões metodológicas que se aproximam da tendência construtivista, na medida, em que na proposta do PPP, é elucidado que os professores de forma colaborativa, participativa, desenvolverão uma prática educativa baseada em “[...] seminários, gincanas, maquetes, desenhos, festivais, cartazes, vídeos, excursões, palestras, músicas, jogos, pesquisas, trabalhos em grupos, debates, realizações de projetos e visitas a universidade e a indústrias” (PPP, 2019, p.7). 
Com efeito, segundo Mastella, (2016), em concordância com Niemann e Brandolli (2012), estas várias estratégias didáticas se forem mobilizadas pelos professores, sem a obrigação dos afazeres tradicionais, desenvolvem aulas mais dinâmicas, construtivas e reflexivas, atuando como pesquisadores abertos ao diálogo, de modo a propiciar com que os alunos sejam o centro da aprendizagem, o protagonista da construção de seu conhecimento, pode se configurar na perspectiva do construtivismo, considerando que "[...] as práticas pedagógicas desenvolvidas na escola promovem o desenvolvimento na medida que o aluno, como sujeito ativo, participa das atividades de maneira construtiva [...]" (Niemann \& Brandoli, 2012, p.9).

Nesta perspectiva, é importante salientarmos que não basta que a escola sinalize diferentes métodos de ensino em sua proposta pedagógica, pois, de acordo com Souza (2015), é incumbido ao professor o papel de ser criativo, pesquisar e renovar a cada dia sua metodologia, para melhor desenvolvimento do processo de ensino e aprendizagem. Entretanto, para melhor abordagem do conteúdo em sala de aula e melhor compreensão deste, Souza e Silva (2021) afirmam que cabe ao professor compreender as potencialidades e limitações do aluno inserido no contexto escolar. Isso torna fundamental que na lógica construtivista seja oportunizado organizações didáticas que favoreçam os alunos a serem protagonistas de diversas interações (Freire, 2017), propiciando a zona de desenvolvimento proximal apontada por Vygotsky (1991). Conforme Zabala (1998):

É todo um conjunto de interações baseada na atividade conjunta dos alunos e dos professores, que encontram fundamento na zona de desenvolvimento proximal, que, portanto, vê o ensino como um processo de construção compartilhada (Zabala, 1998, p.91).

Para o autor, na concepção construtivista, não é suficiente que os alunos se encontrem frente ao conteúdo a aprender, “[...] é necessário que diante destes possam atualizar seus esquemas de conhecimento, compará-los com o que é novo, identificar semelhanças e diferenças e integrá-las em seus esquemas” (Zabala, 1998, p.37).

Do ponto de vista dos métodos de ensino, um aspecto bem sinalizado no PPP é o trabalho com projetos, com destaque aos projetos de incentivo à leitura e escrita e o uso dos projetos como forma de vincular o processo ensino-aprendizagem com a realidade dos alunos. "Os projetos serão estruturados de acordo com a necessidade, interesse do educando e em observância a proposta curricular (PPP, 2019, p.12).

Depreendemos que o trabalho com projetos é um caminho possibilitador para a materialização da abordagem construtivista no contexto escolar. Zabala (1998) nos apoia nesta análise ao citar a importância do trabalho com projetos e sinalizar que o ponto de partida do método de projetos é o esforço e o interesse dos alunos de modo a se envolver no processo. "O método de projeto designa a atividade espontânea e coordenada de um grupo de alunos que se dedicam metodicamente à execução de um trabalho globalizado e escolhido livremente por eles mesmos". Assim, ao nosso ver, o trabalho com projetos é uma estratégia que traduz uma concepção construtivista, pois os alunos podem, por meio de projetos, problematizar a sua realidade vivida, se envolver em sua aprendizagem e envolver-se em diversas interações entre os colegas. Conforme Zabala (1998), os alunos, ao elaborar projetos e a executá-los, tornam-se protagonistas em sua aprendizagem.

No documento, o aluno é "[...] agente na criação e integrante com o meio ambiente" (PPP, 2019, p.7) e responsável pela construção de sua " [...] autonomia, autodeterminação, responsabilidade, cooperação e solidariedade, aprende a trabalhar ideias, pensamentos e assimila códigos de conduta padronizados de comportamento coletivo (PPP, 2019, p.7). Aspectos que evidenciam bem uma abordagem construtivista, uma vez que, conforme Gregório e Pereira (2012), na concepção ensino aprendizagem construtivista,

$\mathrm{O}$ aluno atua com ator principal da aquisição do seu conhecimento, se apropria do que aprende, no momento certo, utilizando e ampliando todo seu potencial com esforço e ritmo próprio e professor nesse processo atua como ator coadjuvante, de forma a facilitar as etapas evolutivas dessa construção (Gregório; Pereira, 2012, p.53). 
Em concordância com os ensinamentos de Gregório; Pereira (2012), Guimarães e Maciel (2021) acrescentam que é necessário que haja afetividade entre professor e aluno para propiciar a troca de conteúdo de maneira mais envolvente, tornando os alunos mais motivados e capazes de compreender melhor o que está sendo lecionado. E, para que aconteça essa afetividade, "o professor precisa desenvolver, em si mesmo, uma certa sensibilidade para ouvir o seu aluno, e conhecer a sua realidade, assim como, criar um clima afetivo dentro de sala de aula." (Guimarães \& Maciel, p.10; 2021)

\section{Conclusão}

Ao propormos nesta pesquisa identificar se as ações educativas para o processo ensino-aprendizagem prevista no PPP são balizadas na abordagem construtivista, constatamos que apesar de não haver evidências teóricas sobre o construtivismo, várias ações previstas no documento se amparam no construtivismo.

No que tange às evidências teóricas sinalizadas por meio das metodologias adotadas na escola, observamos que apesar de não estarem presentes no documento, é explicitado suporte de modo especial nas tendências pedagógicas da linha progressista, sendo apontado no documento as tendências libertadoras da educação de linha progressista e sócio-histórica. Isto fica evidente ao inferir à escola a atribuição de formação da consciência política do aluno para a transformação de sua própria realidade.

Do ponto de vista da abordagem de ensino construtivista, apesar desta abordagem não aparecer de forma explícita no documento, constatamos evidências traduzidas nos objetivos e nos aspectos metodológicos propostos para o ensino. Os objetivos e as evidências se traduzem pela forma como as práticas de ensino são orientadas, em que há fortes preocupações com os aspectos cognitivos, afetivos, socioculturais, bem como a formação para a construção da autonomia do aluno em processo de aprendizagem, a formação para resolução de problemas e o trabalho de forma colaborativa. Não obstante, é notório o papel do professor e aluno, em que a relação entre alunos e professores se dá de forma harmoniosa e de respeito mútuo, sem a tradicional postura autoritária do professor, traduzindo oportunidades à formação vinculada com a vida dos alunos, de modo a despertar a sua curiosidade para a resolução de problemas.

Assim, as ações propostas para o ensino-aprendizagem, se alicerçam em ações colaborativas, propiciando ao aluno a condição de ser o centro da aprendizagem. Ademais as orientações para as metodologias de ensino, se baseiam em várias estratégias e recursos didáticos, tais como seminários, gincanas, festivais, músicas, jogos, pesquisas, trabalhos em grupos, trabalho com projetos, debates, uma perspectiva pedagógica que se aproxima da tendência construtivista.

Sobretudo, podemos dizer que o objetivo da abordagem pedagógica em questão é fazer com que o ensino esteja ao alcance de cada aluno, com aulas interativas e democratizadas, mediadas pelo professor, respeitando suas dificuldades, diferenças individuais e culturais, bem como valorizando seus esforços, independentemente de seus erros ou acertos sendo que a relação entre professor e aluno acontece com equilíbrio e respeito.

Os resultados são indicadores da importância de no PPP estar explícito as correntes teóricas que dão suporte as práticas efetivas que ocorrem no contexto da escola e, sobretudo, que este documento seja construído de forma coletiva, traduzindo os desejos, inquietações e necessidades de toda comunidade escolar. Para tanto, é fundamental que os professores tenham conhecimento sobre as diversas tendências pedagógicas que dão suporte as práticas escolares e sua prática de ensino.

Assim ao encerrar esta reflexão, reconhecemos as suas lacunas em termos de análise da proposta pedagógica da escola, porquanto, não é possível identificar e salientar todas as multifaces do documento e das práticas que de fato se materializam no cotidiano escolar. Contudo, as reflexões aqui tecidas são base para futuras pesquisas, em que procuraremos aprofundar nossas reflexões teóricas de forma buscar novas propostas de abordagens construtivistas a serem materializadas no cotidiano da escola. Apriori, já desenhamos algumas questões, que por certo, conduzirão futura investigação: Quais são as orientações previstas no PPP que direcionam para a relação professor-aluno com vistas ao diálogo e a construção do 
conhecimento pelos alunos? Como a abordagem construtivista pode apoiar os aspectos teóricos e práticos da construção do PPP bem como as práticas de ensino dos professores da escola pesquisada?

\section{Referências}

Bessa, V. H. (2008). Teorias da Aprendizagem. Ed. IESDE Brasil S.A.

Calado, S. S. \& Ferreira, S. C. R. (2004/2005). Análise de Documentos: Método de recolha e análise de dados 1 DEFCUL.

Chakur, C. R. S. L. \& Silva, R. C. \& Massabni, V. G. (2004). O Construtivismo no Ensino Fundamental: um caso de desconstrução. In: 27a. Reunião Anual da $A N P E d$, Caxambu. Sociedade, Democracia e Educação: UNESP. p. 1-18.

EMEF Selva Campos Monteiro. (2019). Projeto Político Pedagógico - PPP. Rio Verde-GO.

Freire, P. (1996). Pedagogia da Autonomia: saberes necessários à prática educativa. e Terra.

Freire, P. (1997) Educação Como Prática da Liberdade, Paz e Terra.

Gregório, M. P. F. \& Pereira, P. S. (2012). Construtivismo e aprendizagem: uma reflexão sobre o trabalho docente. Educação, 2(1),.51-66.

Guimarães, M. S. \& Maciel, C. M. L. A. (2021). A afetividade na relação professor-aluno: Alicerces para a aprendizagem significativa. Rev Research, Society and Development, $10(10), 1-12$

Gurgel, T. (2019) 8 Questões Essenciais Sobre o Projeto Político Pedagógico. Rev.Nova Escola. https://gestaoescolar.org.br/conteudo/799/8-questoesessenciais-sobre-projeto-politico-pedagogico.

Lüdke, M. André, M. E. D. A. (2013). Pesquisa em educação: abordagens qualitativas. (2a ed.), E.P.U.

Mastella, I. C. R. et al. (2014). A teoria Piagetiana na Educação Atual: Um Retorno necessário. In.: XVI Congresso Internacional de Educação no Mercosul. Cruz Alta.

Marinho, M. M. (2016). O Sentido do Construtivismo na Educação Infantil.

Niemman, F. A. \& Brandoli, F. (2012). Jean Piaget. Um aporte teórico para o construtivismo e suas contribuições para o processo de ensino e aprendizagem da Língua Portuguesa e da Matemática. Atas da IX ANPED SUL: Seminário de pesquisa em educação da região sul.

Oliveira, J. F. (2008). A Construção Coletiva do Projeto Político Pedagógico da escola. Cultura Acadêmica. Disponível no moodle3. Mec.gov. BR/uft.

Paniago, R. N. (2017). Os professores, seu saber e seu fazer: elementos para uma reflexão sobre a prática docente. Appris.

Santos, F. M. (2007). Significações de construtivismo na perspectiva de professores “Construtivistas” e sua relação com práticas avaliativas. Dissertação de Mestrado. Brasília, UNB.

Souza, A.P. \& Rosso, A. J. (2011). Mediação e Zona de Desenvolvimento Proximal. (ZDP): entre pensamentos e práticas docentes. In: CONGRESSO NACIONAL DE EDUCAÇÃO: EDUCERE, 10. 2011, Curitiba. Anais... Curitiba: CHAMPAGNAT, v. 1, p. 5894 - 5906.

Souza, J. R. \& Silva, A. O.V. (2021). Fatores que interferem no processo de ensino e aprendizagem. Rev. Research, Society and Development, 10 (6), 1-12, https://rsdjournal.org/index.php/rsd/article/view/20366.

Souza, L. F. (2015). Práticas Pedagógicas e Metodologia de Paulo Freire. São Sebastião do Paraíso-MG.

Veiga, I. P. A. (org.) (2013). Projeto político- pedagógico da escola: uma construção possível. (29a.ed). Papirus.

Vygotsky, L. S. (1991) A formação social da mente. (4a ed). Livraria Martins Fontes Editora Ltda.

Zabala, A. (1998). A prática educativa: como ensinar. Artmed. 